\title{
Reações paradoxais no tratamento da tuberculose
}

Senhor Editor:

As reações paradoxais no tratamento da tuberculose (RPTT) são exacerbações de sintomas, localizados ou sistêmicos, que ocorrem após melhora da doença proporcionada pelo mesmo tratamento. Tais reações parecem ser relacionadas à emergência, recrudescimento ou incremento da hipersensibilidade antes inexistente ou deprimida, sendo bem estabelecida sua independência das reações adversas relacionadas ao uso ou interações das drogas antituberculosas ${ }^{29}$. Embora descritas desde os primórdios da quimioterapia antituberculosa ${ }^{5141930}$, eram de ocorrência rara, apresentando um acentuado aumento entre os portadores da co-infecção pelo Mycobacterium tuberculosis o HIV, especialmente após o advento da terapia antirretroviral ${ }^{322}$.

As mais freqüentemente relatadas, inclusive no país, são as exacerbações de sintomas neurológicos seguido de linfadenomegalias e derrames pleurais 41012114161719 2930 . Diversas outras já foram descritas, tais como, derrames peritoneais, infiltrados miliares, cavidades pulmonares, hemoptises, linfangites, febres ou mesmo insuficiência respiratória aguda ${ }^{3511141823}$.

É quase certo que as RPTT se relacionem ao incremento da hipersensibilidade porém ainda não foram suficientemente esclarecidos todos os mecanismos imunológicos e inflamatórios, o comportamento da população bacilar e o papel da medicação.

Em estudo prospectivo, Narita e cols ${ }^{22}$ mostraram que 6 de 7 pacientes com AIDS e baixas taxas de CD4 que apresentaram RPTT relacionadas ao início da terapia anti-retroviral, converteram o teste tuberculínico de negativo para positivo, o que contribui para firmar uma relação entre estes fenômenos e a hipersensibilidade. Não existem trabalhos semelhantes em pacientes HIV-negativos, mas a ocorrência das reações informadas nestes pacientes, são quase unânimes em descrevê-las exatamente quando os pacientes experimentam uma melhora clínica com o uso da medicação. Portanto, podem nesta melhora, recuperar uma hipersensibilidade tuberculínica bloqueada ou reprimida 45192329 .

Junto com colaboradores, publicamos em 1997, um caso de rápida formação de cavidade pulmonar tuberculosa em paciente com AIDS, que se manifestou após melhora clínica, ganho ponderal e viragem tuberculínica com a quimioterapia antituberculosa, antes da introdução de qualquer terapia antiretroviral. Mesmo diante de um paradoxo, na comunicação, não definimos o fenômeno como uma RPTT ${ }^{11}$.

Início agudo ou o incremento dos sintomas na tuberculose foram relatados e relacionados à hipersensibilidade tuberculínica, antes e depois do advento da quimioterapia 16182631 . Para antigos tisiologistas, cerca de $85 \%$ dos pacientes apresentavam início da doença insidioso e sintomas progressivos, enquanto $25 \%$ expressavam a doença de forma aguda ${ }^{16}$. Manifestações como a hemoptise do alerta ou do latido em jovens aparentemente hígidos, a vômica do esvaziamento cavitário, a febre alta e persistente do derrame pleural, a escrofulização de linfadenomegalias, a insuficiência respiratória aguda das formas miliares granúlicas ou as manifestações neurológicas provocadas pela expansão de granulomas foram descritas e relacionadas à hipersensibilidade pelos antigos tisiologistas. Alguns destes quadros eram observados no afloramento de sintomas de formas classificadas como tuberculose oculta, inapercepta ou inaparente ${ }^{816182532}$. O paradoxo acontece quando manifestações semelhantes emergem durante a quimioterapia e após o paciente experimentar uma melhora clínica.

De acordo com os conhecimentos atuais, sabe-se que a resposta da hipersensibilidade pode ser relacionada tanto a linfócitos da categoria CD4 como CD8 além de tipos especiais de macrófagos. Está presente em infectados tanto pelo $M$. tuberculosis como pelo $M$. bovis e se expressa pela prova tuberculínica positiva forte, no Brasil, com uso do PPD Rht $23 \geq 10 \mathrm{~mm}$ de enduração. Respostas fracas, $\geq 5$ a $10 \mathrm{~mm}$, sugerem

\footnotetext{
Endereço para correspondência: Dr. Fernando Augusto Fiuza de Melo. R. Santo Estácio 248, Cidade Vargas, 04319-010 São Paulo, SP. Tel: 55 11 5588-4966; Fax: 5511 3885-7827

e-mail: f.fiuza@terra.com.br

Recebido para publicação em 10/10/2001.
} 
infecções por micobactérias não tuberculosas. A vacinação BCG, uma amostra obtida por mutação do bacilo bovino, provoca resposta absolutamente sobreponível a da infecção natural, ou seja, positiva forte, que com o tempo apresenta uma tendência à diminuição da enduração.

A hipersensibilidade se estabelece plenamente 3 a 7 semanas após a infecção natural ou a artificialmente induzida por vacina, período conhecido como prétuberculínico. A depleção, diminuição ou mesmo desaparecimento da hipersensibilidade pode acontecer em indivíduos com imunodepressão tais como: desnutrição, desvios alimentares (vegetarismo), estados consuptivos, uso de drogas imunossupressoras, viroses, vacinas com vírus vivos, AIDS, sarcoidose, micoses, neoplasias, diabetes, gastrectomizados, etc. A interrupção ou modificação destas condições favoreceria o retorno ou o incremento da reatividade tuberculínica. Bloqueio temporário da hipersensibilidade pode ocorrer por depleção do linfócito memória, nas formas graves da tuberculose, na tuberculose pleural, por bloqueio de células aderentes (macrófagos imunossupressores?), polo não reativo da doença e outras circunstâncias, inclusive em situações de stress físico ou emocional. Assim, a hipersensibilidade retorna em uma nova prova tuberculínica quando cessa a situação de bloqueio, por ativação da memória imunológica estimulada por uma prova anterior (booster) ou após a melhora por tratamento (RPTT). Pode-se intuir, que no caso das RPTT, o retorno da resposta se liga a antígenos ou outros agentes estimulantes que se liberam quando bacilos persistentes ou latentes são destruídos pelo retorno da atividade imunológica ou pela medicação. A irradiação pode também destruir bacilos, o que explica o aparecimento de cavitações de nódulos silenciosos com a aplicação de radioterapia12679182021242731.
Nos estudos dos pacientes HIV-negativos não há referências sobre aspectos da resposta imunológica, ou seja, quais as células e como estas participam do processo das RPTT. Entre os portadores de AIDS, com base no estudo de Narita e cols, as RPTT se relacionam ao início do tratamento anti-retroviral e a uma melhora substancial da resposta imune e o retorno da hipersensibilidade ${ }^{22}$.

Há, entretanto, que se considerar outras questões.

Ainda que relacionadas, a hipersensibilidade e a imunidade, constituem fenômenos independentes de acordo com as seguintes evidências postuladas por Youmans ${ }^{33}$ :

- cobaia dessensibilizada com tuberculina mantém sua imunidade.

- não há correlação entre o grau de hipersensibilidade e o grau de imunidade.

- componentes protéicos extraídos de cepas do M. tuberculosis que induzem hipersensibilidade não induzem imunidade.

- ratos vacinados com frações do RNA bacilar desenvolvem imunidade mas não hipersensibilidade.

- linfócitos extraídos de ratos vacinados não liberam MIF (fator de inibição de migração de macrófagos) após estimulação antigênica com tuberculina.

Com base nestes postulados, não haveria um retorno da hipersensibilidade somente porque volta a imunidade. Pode aquela acompanhar o retorno desta, mas, provavelmente outros fatores devem concorrer para a volta da hipersensibilidade, entre estes a ação dos medicamentos e, possivelmente, a melhora do estado geral. Uma tentativa de esquematizar a patogenia da RPDTT é apresentada na Figura 1 mostrada em seguida.

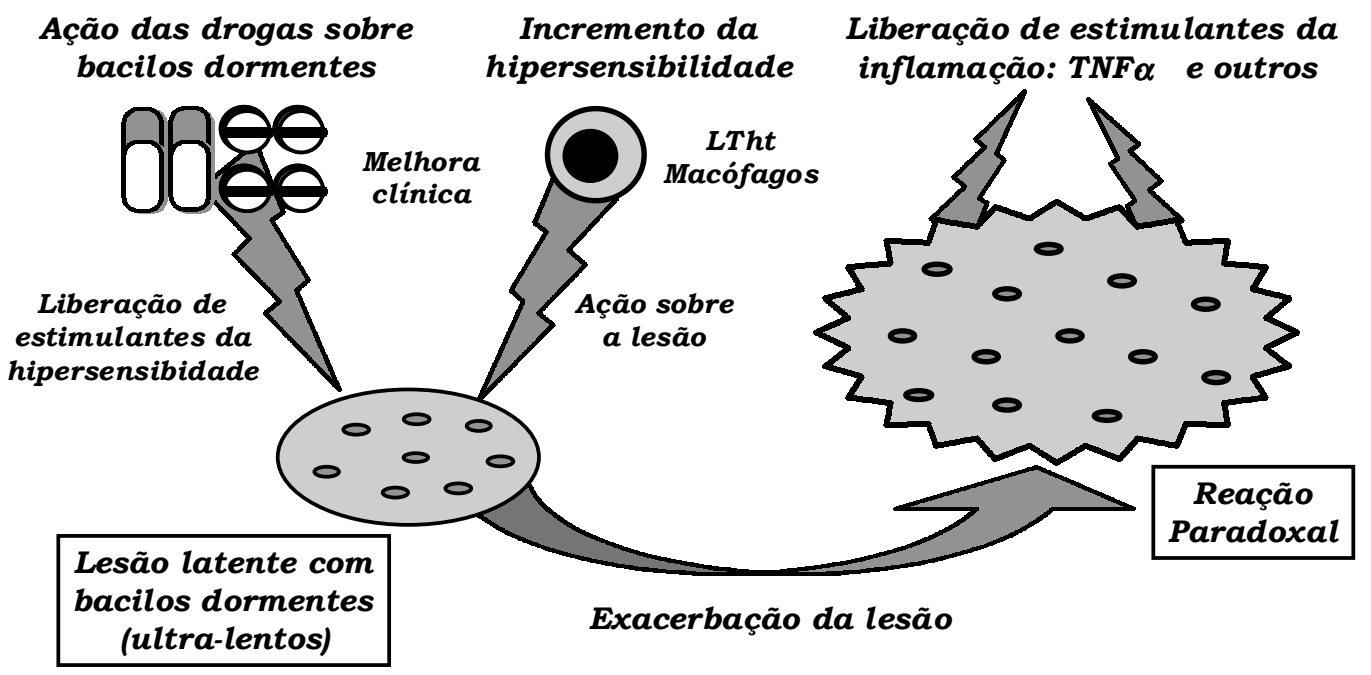

Figura 1 - Reações paradoxais durante o tratamento da tuberculose (Provável patogenia - esquemática). 
Quanto ao processo inflamatório, alguns autores se referem a uma expansão de granuloma latente reativado e edema ${ }^{34102229}$. Entretanto, outros exemplos de RPTT também explicados por uma reativação da hipersensibilidade, apresentam diferentes comportamentos inflamatórios, como a liquefação do cáseo, vasculites, acúmulo celular e aumento da produção de TNF- $\alpha$, entre outros.

Outro problema ainda não esclarecido refere-se ao comportamento da população bacilar. Considerando que manifestações de hipersensibilidade podem ocorrer em formas paucibacilíferas da tuberculose 23252632 , qual seria o comportamento das populações bacilares na RPTT: aumentam ou permanecem inalteradas, só importa o processo inflamatório?

Finalmente, qual o papel da medicação seja a antituberculosa como a anti-retroviral? Observando os casos estudados e revistos por Teoh e cols ${ }^{29}$, além de outros, nota-se uma clara diferença de tempo entre o início do tratamento e o aparecimento das RPTT. Antes do surgimento da rifampicina (RMP) e da terapia de curta duração, manifestações paradoxais eram, em sua maioria, de ocorrência tardia, com um período de latência marcado por meses; já com a RMP, elas são bem mais precoces, com latência semanais. Ao apresentarmos, em 1989, um caso de reação paradoxal neurológica, o primeiro por nós observado, comentamos a possibilidade da interferência da atividade esterilizante da RMP no desencadeamento da mesma. Sendo uma droga de boa difusão pela barreira liqüórica e alto poder esterilizante destruiria bacilos dormentes em focos latentes, liberando antígenos bacilares, relacionados à expansão de granulomas. Gutierrez ${ }^{13} \mathrm{em}$ tese de doutorado apresentada à Faculdade de Medicina da USP, estudando a morfologia das lesões pulmonares em necrópsias de pacientes infectados pelo HIV com tuberculose, mostrou que elas se apresentavam com elevada freqüência como nódulos exsudativos, sem necrose caseosa, presença de neutrófilos e bacilos numa reação granulomatosa incompleta, diferente das lesões de granuloma observadas em pacientes sem infecção pelo HIV. Desse modo, a introdução do tratamento anti-retroviral e antituberculoso poderiam refazer a reação granulomatosa específica e plena da tuberculose, desencadeando o aparecimento de sintomas a ela correlacionados.

Quanto à conduta frente a emergência das RPTT, em geral, os trabalhos publicados mostram que os casos evoluíram para a cura com a continuidade do tratamento, não sendo necessário a modificação do esquema antituberculoso, em alguns casos apenas seu prolongamento. Quase todos indicam corticoesteróides por um prazo determinado pela remissão da manifestação paradoxal. Esta observação é capital, pois na verdade as RPTT não representam uma falência do tratamento, mas uma conseqüência dos bons resultados deste. No caso de pacientes portadores de AIDS, segundo o CDC, também não há necessidade de alteração da terapia anti-retroviral estabelecida3410141629.

Para concluir, pode-se afirmar que as RPTT ainda não foram estudadas adequadamente, permanecendo incompleto o conhecimento sobre sua patogenia. Com os recursos atuais, certamente que constitui um campo tentador de pesquisa.

\section{Fernando Augusto Fiuza de Melo \\ Médico do Instituto Clemente Ferreira e \\ Serviço de Doenças do Aparelho Respiratório - São Paulo}

\section{REFERÊNCIAS BIBLIOGRÁFICAS}

1. Afiune JB. Clínica e Diagnóstico. In: Veronesi R, Focaccia R (eds) Tratado de Infectologia, Editora Atheneu, São Paulo, cap.74, 4:919-925, 1997.

2. Bates $\mathrm{JH}$. Transmission and pathogenesis of tuberculosis. Clinical in Chest of Medicine 1:167-174, 1980.

3. Center Diseases Control. Recommendations and reports. MMWR 47:10-11, 1998.

4. Chambers ST, Hendrickse WA, Record C, Rudge P, Smith H. Paradoxal expansion of intracranial tuberculosmas during chemoterapy. Lancet 2:181-183, 1984.

5. Choremis CB, Padiatellis C, Zoumboulakis D, Yannakos D. Transitory exarcebation of fever and roentgenographic findings during treatment of tuberculosis in children. American Review of Tuberculosis 72:527-536, 1955

6. Daniel TM. The immunology of tuberculosis. Clinical in Chest of Medicine 1:189-201, 1980.

7. Dannenberg Jr AM. Immune mechanisms in the pathogenesis of pulmonary tuberculosis. Review of Infetion Diseases 2 (suppl II):369-378, 1989.
8. De Paula A. Tuberculose inaparente, Livraria Odeon, Rio de Janeiro, 1945.

9. Ellner JJ. Regulación de la respuesta inmune celular frente al Mycobacterium tuberculosis. El mecanismo de depressión selectiva de la respuesta ao PPD. Boletin de la Union Internacional Contre la Tuberculosis e las Enfermidades Respiratorias 19:141-145, 1991.

10. Fiúza-de-Melo FA, Souza WM, Santoro IL, Barros LA. Expansão paradoxal de tuberculoma cerebral durante quimioterapia antituberculosa. (Mural). In: Anais do III Congresso Paulista de Pneumologia e Tisiologia, 1989.

11. Fiúza-de-Melo FA, Valery MIB, Miki DY, Magalhães CG. Cavidade pulmonar tuberculosa de rápida formação em paciente portador de VIH/SIDA. Boletim de Pneumologia Sanitária 5:90-97, 1997.

12. Guanaes AG, Andrade Filho A, Cruz AA, Martins ACP, Neves CMC, Lemos ACM. Expansão paradoxal de lesão de tuberculose 
cerebral durante o uso de tuberculostáticos. TL.484 In: Resumos do XXVI Congresso Brasileiro de Pneumologia e Tisiologia. Jornal de Pneumologia 18 (supl II):123, 1992.

13. Gutierrez EB. Influência da infecção pelo vírus de imunodeficiência humana e do tratamento antimicrobiano na morfologia da micobacteriose pulmonar. Tese de doutorado apresentada a Faculdade de Medicina da Universidade de São Paulo, 1999.

14. Hill AR, Mateo F, Hudak A. Transient exacerbation of tuberculosis lymphadenitis during chemoterapy in patients with AIDS. Clinical Infections Diseases 19:774-776, 1994.

15. Ibiapina A. Início e evolução da tuberculose pulmonar no adulto. Editora Científica, Rio de Janeiro, 1945.

16. Lees AJ, Macleod AF, Marshall J. Cerebral tuberculous developing during treatment of tuberculosis meningitis. Lancet 1:1208-1211, 1980.

17. Loizou LA, Anderson M. Intracranial tuberculomas: correlation of computerized tomography with clinco-pathological findings. Quarterly Journal of Medicine 201:104-114, 1982.

18. Lordi GM, Reichman LB. Tuberculin skin testing. In: Schlossberg D (ed) Tuberculosis. Spring-Verlag New York Inc. p. 33-38, 1988.

19. Matthay RA, Neff TA, Iseman MD. Tuberculous pleural effusions developing during chemotherapy for pulmonary tuberculosis. American Review of Respiratory Diseases 109:469-472, 1974.

20. Ministério da Saúde. Manual de Normas para o controle da tuberculose. DNPS Brasília, 2000.

21. Molloy A, Kaplan G. Cells-mediated imune response. In: Rom WN, Garay SM (eds) Tuberculosis. Little, Brown and Co. New York; cap. 25, p. 305-314, 1995.

22. Narita M, Ashkin D, Hollender ES, Pitchenick AE. Paradoxal worsening of tuberculosis following antiretroviral therapy in patients with AIDS. American Journal of Respiratory and Critical Care Medicine 158:157161, 1998.
23. Onwubalili JK, Scott GM, Smith H. Acute respiratory distress related to chemotherapy of advanced pulmonary tuberculosis: a study of two cases and review of the literature. Quartely Journal of Medicine 230:599-610, 1986.

24. Orme IM, Andersen P, Boom WT. T cells response to Mycobacterium tuberculosis. Journal of Infection Diseases 167:1481-1497, 1993.

25. Ribeiro SN, Gerhardt Filho G, Lapa e Silva JR, Souza GRM. Tuberculose. In: Bethlem N (ed) Pneumologia, $4^{\text {a }}$ Edição, Atheneu, São Paulo, cap. 28 p. 379-448, 1995.

26. Rich AR. Patogenia de la tuberculosis (versión castellaña) Editorial Alfa, Buenos Aires, 1948.

27. Ruffino Netto A. Prova tuberculínica. Revista da Associação Médica Brasileira 25:257-259, 1979.

28. Tapia M. Formas anatomoclínicas, diagnostico y tratamiento de la tuberculosis pulmonar. $2^{a}$ edition. Livraria Luso-Espanhola Ltd ${ }^{a}$ Barcelona, 1946.

29. Teoh R, Humphries MJ, O' Mahony SG. Symptomatic intracranial tuberculoma developing during treatment of tuberculosis: a report of 10 patients and review of the literature. Quarterly Journal of Medicine 63:449-460, 1987.

30. Thrush DC, Barwick DD. Three patients with intracranial tuberculomas with unusual features. Jornal of Neurology, Neurosurgery and Psychiatry 37:566-569, 1974.

31. Youmans GP. Development of delayed (tuberculin) hipersensitivity in tuberculosis. In: Youmans GP (ed) Tuberculosis. WB Saunders Co, Philadelphia, cap. 7, p. 209-224,1979.

32. Youmans GP. Pathogenesis of tuberculosis. In: Youmans GP (ed) Tuberculosis. WB Saunders Co, Philadelphia, cap. 14, p.317$326,1979$.

33. Youmans GP. Relationship between delayed hypersensitivity and immunity in tuberculosis. In: Youmans GP (ed) Tuberculosis. WB Saunders Co, Philadelphia, cap. 13, p. 302-316,1979. 